\title{
Big Sleep: Beyond Propofol Sedation During GI Endoscopy
}

\author{
Basavana Goudra ${ }^{1}$
}

Published online: 19 September 2018

(c) Springer Science+Business Media, LLC, part of Springer Nature 2018

In the USA, endoscopic procedures are usually performed on sedated patients, which improves overall patient acceptance and comfort while improving procedural safety, efficiency, and quality [1]. A range of sedation depth is available, from moderate sedation on the one hand to general anesthesia on the other. Although during general anesthesia patients are not arousable even by painful stimulation, moderate sedation ("conscious sedation") is characterized by depression of consciousness during which patients respond purposefully to verbal commands, either alone or accompanied by light tactile stimulation. At least in the USA, deep sedation is preferred by both patients and their gastroenterologists.

The American Society of Anesthesiology defines deep sedation as a drug-induced depression of consciousness during which patients cannot be easily aroused but respond purposefully following repeated or painful stimulation. Since during sedation the patient's ability to independently maintain ventilatory function may be impaired, they may thus require assistance in maintaining a patent airway; furthermore, spontaneous ventilation is likely to be inadequate although cardiovascular function is usually maintained [2]. Often, the state of deep sedation slips into general anesthesia, including deep general anesthesia, especially when sedatives are administered by anesthesia providers [3].

Propofol is regarded as the sine qua non agent for gastroenterological endoscopic sedation. In spite of many publications highlighting the dangers of propofol sedation in patients undergoing endoscopic procedures, it remains the most popular sedative agent in North America for endoscopic sedation. Some of the major attractions of propofol sedation are rapid onset of action, rapid recovery, low incidence of post-procedure nausea and vomiting, and high degree of patient satisfaction. The safety record is mixed

Basavana Goudra

Basavana.Goudra@uphs.upenn.edu

1 Departments of Anesthesiology and Critical Care Medicine, Perelman School of Medicine, Hospital of the University of Pennsylvania, 680 Dulles, 3400 Spruce Street, Philadelphia, PA 19104, USA depending on the person administering the propofol and the dose administered. Both apnea and laryngospasm may occur which will not be discussed further. Aspiration is another known risk factor, largely related to suppression of laryngeal reflex. Moreover, colonic perforation occurs with higher frequency in patients undergoing colonoscopy with propofol deep sedation. While such sedation-related adverse events are typically frequent when propofol was administered by anesthesia providers, they are significantly lower in the hands of non-anesthesia providers [4, 5] most likely since anesthesia providers administer higher doses of propofol than do non-anesthesia providers [6]. The same observation explains the observed superior patient and endoscopist satisfaction in the groups of patients where anesthesia providers administered propofol. A remarkable degree of patient and endoscopist satisfaction is at the core of propofol success story.

Almost every agent capable of producing deep sedation has been tried in patients undergoing GI endoscopy. Etomidate was invented and approved for clinical use few years earlier than propofol, with an unparalleled degree of cardiovascular stability as its major attraction and the selling point. Adrenal suppression, especially in critically ill patients, is its main drawback since it exhibits a dose-dependent inhibition of adrenal mitochondrial 11- $\beta$ hydroxylase, the enzyme responsible for the final conversion of 11-deoxycortisol to cortisol. Although adrenal suppression was touted as a problem in only sick patients receiving a continuous infusion, it is also observed with induction doses. This adverse effect was considered responsible for the increased mortality associated with etomidate and is considered to be specifically detrimental in septic patients who may have a baseline adrenal insufficiency due to critical illness [7]. Nevertheless, patients with poor cardiovascular reserve (and not septic) are frequently endoscoped as inpatients or as outpatients, including patients with a low ejection fraction, biventricular pacemaker implantation, and other serious cardiac comorbidities. As an example of the need for sedated procedures performed in patients with serious cardiac morbidity, colonoscopy is 
often performed, frequently on an outpatient basis, prior to cardiac transplantation.

In a prospective double-blinded randomized controlled trial comparing etomidate and propofol sedation for complex upper endoscopic procedures, Kim et al. [8] reported fewer respiratory depression events and superior sedative efficacy for etomidate compared with propofol. Thus far, there have been no comparative studies of patient and endoscopist satisfaction in patients undergoing gastro-intestinal (GI) endoscopy. In this issue of Digestive Diseases and Sciences, Lee et al. published the results of their findings in relation to patient satisfaction among patients undergoing advanced endoscopic procedures [9]. In this randomized non-inferiority trial, balanced endoscopic sedation was achieved using midazolam and fentanyl, followed by either propofol or etomidate as an add-on drug in a randomized fashion. The doses of both propofol and etomidate were tailored to achieve moderate, but not deep sedation. As expected, the incidence of cardiopulmonary adverse events (including respiratory and cardiovascular) were lower in the etomidate group. Moreover, the incidence of adverse respiratory events such as hypoxia was lower with etomidate. Three patients receiving etomidate experienced rigidity or tremor after sedation. Most importantly, satisfaction of endoscopists and nurses and patient's cooperation in the etomidate group was non-inferior when compared to the propofol group. In essence, where appropriate, etomidate may be used to provide appropriate levels of sedation to successfully complete advanced endoscopic procedures with a degree of satisfaction similar to propofol. Given the limited experience with etomidate in patients undergoing GI endoscopy, these findings are important and should encourage providers to use this drug where appropriate such as in candidates that have limited cardiovascular reserve in the absence of sepsis, where propofol may be undesirable. Nonetheless, one might circumvent the cardiovascular adverse events associated with propofol by preemptive administration of inotropes and/or vasopressors.

Other than etomidate, several other anesthetics have seen little use as sedatives for GI procedures. Ketamine is another agent capable of producing deep sedation, though inadequately explored in the setting of GI endoscopy [10]. Its range of effects includes analgesia, amnesia, anesthesia, and sedation. Major drawbacks include unusual and unfamiliar patient responses such as a conscious-appearing patient that can be unnerving for endoscopists when intubating the esophagus as an example [11]. An increased incidence of laryngospasm is also well documented. Necessary administration of an antisialagogue such as atropine or glycopyrrolate in order to suppress profuse salivation produces uncomfortable anticholinergic side effects such as dry mouth. In adults, it can trigger visual and auditory hallucinations which can lead to the nightmares, thereby limiting its clinical usefulness. Prior administration of benzodiazepines may avoid this particular drawback, although benzodiazepines might prolong the discharge times in the setting of outpatient GI endoscopy. Its ability to maintain spontaneous ventilation and hemodynamic stability is an advantage in a subset of patients undergoing endoscopy. The former category includes morbidly obese, patients with potential airway difficulties such as sleep apnea and those with poor respiratory reserve. Currently, the place of ketamine is at best as an additive to other agents like propofol. The drug might also be particularly suitable in pediatric GI endoscopy.

Dexmedetomidine is a relatively new sedative that is likely to have a small but definite place in the field of GI endoscopy [12]. Experience with this drug is also limited in the field of GI endoscopy sedation. Similar to clonidine (a known antihypertensive agent), it is an $\alpha-2$ receptor agonist, although specificity for these receptors is $8 \times$ higher than clonidine. In doses employed for sedation, it has negligible respiratory depressant activity. The activation of postsynaptic $\alpha-2$ receptors produces sympatholysis with resultant hypotension and bradycardia. Although the drug possesses analgesic, amnesic, sedative, and anxiolytic properties, its slow onset and prolonged recovery are a major drawback, especially in the setting of outpatient GI endoscopy. As a sole agent, it is unlikely to have any practical application for advanced endoscopic procedures.

In conclusion, propofol remains the drug of choice in the vast majority of patients that require deep sedation for their GI endoscopy. Nevertheless, there are a small group of patients who might not be the appropriate candidates for propofol-induced sedation. A knowledge of alternative options is essential; accordingly, we have summarized the pros, cons and indications for propofol and its alternatives in Table 1. 
Table 1 Pros and cons of sedatives used for endoscopic sedation

\begin{tabular}{|c|c|c|c|}
\hline Agent & Pros & Cons & Most likely patients to benefit \\
\hline Propofol & $\begin{array}{l}\text { Rapid onset of action } \\
\text { Rapid recovery } \\
\text { Low incidence of PONV } \\
\text { High degree of patient and endoscopist } \\
\text { satisfaction }\end{array}$ & $\begin{array}{l}\text { Difficult to titrate the depth of sedation } \\
\text { High risk of aspiration } \\
\text { Higher incidence of, perforation and } \\
\text { bleeding (during colonoscopy) }\end{array}$ & $\begin{array}{l}\text { The majority of patients undergoing } \\
\text { GI endoscopy including advanced } \\
\text { procedures, as long as the provider is } \\
\text { capable of managing adverse events }\end{array}$ \\
\hline Etomidate & $\begin{array}{l}\text { High degree of cardiovascular stability } \\
\text { High degree of patient and endoscopist } \\
\text { satisfaction } \\
\text { Lower risk of apnea/hypopnea }\end{array}$ & $\begin{array}{l}\text { Potential for adrenal suppression, } \\
\text { especially in septic patients }\end{array}$ & $\begin{array}{l}\text { Particularly useful for patients with low } \\
\text { cardiac reserve }\end{array}$ \\
\hline Ketamine & $\begin{array}{l}\text { Analgesia } \\
\text { Ability to preserve spontaneous } \\
\text { ventilation and low risk of airway } \\
\text { compromise }\end{array}$ & $\begin{array}{l}\text { Increased salivation, emergence } \\
\text { phenomenon (e.g., hallucination) }\end{array}$ & $\begin{array}{l}\text { As an additive to propofol to reduce the } \\
\text { propofol dosing requirements, thereby } \\
\text { decreasing risk of hypoxemia } \\
\text { Patients with poor cardiovascular reserve }\end{array}$ \\
\hline Dexmedetomidine & $\begin{array}{l}\text { Analgesia } \\
\text { Preserves spontaneous ventilation }\end{array}$ & $\begin{array}{l}\text { Slow onset and slow offset of effect } \\
\text { Hypotension and bradycardia }\end{array}$ & $\begin{array}{l}\text { As an additive to other agents in patients } \\
\text { with potential for airway obstruction }\end{array}$ \\
\hline
\end{tabular}

\section{Compliance with ethical standards}

Conflict of interest The author declares that he has no conflict of interest.

\section{References}

1. Müller M, Wehrmann T. How best to approach endoscopic sedation? Nat Rev Gastroenterol Hepatol. 2011;8:481-490.

2. Blayney MR. Procedural sedation for adult patients: an overview. Contin Educ Anaesth Crit Care Pain. 2012;12:176-180.

3. Goudra B, Singh PM, Gouda G, Borle A, Carlin A, Yadwad A. Propofol and non-propofol based sedation for outpatient colonoscopy-prospective comparison of depth of sedation using an EEG based SEDLine monitor. J Clin Monit Comput. 2015;30:551-557.

4. Wernli KJ, Brenner AT, Rutter CM, Inadomi JM. Risks associated with anesthesia services during colonoscopy. Gastroenterology. 2016;150:888-894; quiz e18.

5. Bielawska B, Hookey LC, Sutradhar R, et al. Anesthesia assistance in outpatient colonoscopy and risk of aspiration pneumonia, bowel perforation, and splenic injury. Gastroenterology. 2018;154:77-85.e3.
6. Goudra BG, Singh PM, Gouda G, et al. Safety of non-anesthesia provider-administered propofol (NAAP) sedation in advanced gastrointestinal endoscopic procedures: comparative meta-analysis of pooled results. Dig Dis Sci. 2015;60:2612-2627.

7. Thompson Bastin ML, Baker SN, Weant KA. Effects of etomidate on adrenal suppression: a review of intubated septic patients. Hosp Pharm. 2014;49:177-183.

8. Kim MG, Park SW, Kim JH, et al. Etomidate versus propofol sedation for complex upper endoscopic procedures: a prospective double-blinded randomized controlled trial. Gastrointestinal Endoscopy. 2017;86:452-461.

9. Han SJ, Lee TH, Yang JK et al. Etomidate sedation for advanced endoscopic procedures. Dig Dis Sci. (Epub ahead of print). https ://doi.org/10.1007/s10620-018-5220-3.

10. Goudra BG, Singh PM. Propofol alternatives in gastrointestinal endoscopy anesthesia. Saudi J Anaesth. 2014;8:540-545.

11. Amornyotin S. Sedation and monitoring for gastrointestinal endoscopy. World J Gastrointest Endosc. 2013;5:47-55.

12. Amornyotin S. Dexmedetomidine in gastrointestinal endoscopic procedures. World J Anesthesiol. 2016;5:1-14. 